\title{
A GESTÃO EDUCACIONAL NAS FORMULAÇÕES DE POLÍTICAS PARA A EDUCAÇÃO BÁSICA NO GOVERNO LULA
}

\author{
EDUCATIONAL MANAGEMENT IN POLICY FORMULATIONS FOR BASIC EDUCATION \\ UNDER THE LULA GOVERNMENT
}

\section{LA GESTIÓN EDUCACIONAL EN LAS FORMULACIONES DE POLÍTICAS PARA LA EDU- CACIÓN BÁSICA EN EL GOBIERNO LULA}

Andréia Vicência Vitor Alves ${ }^{1}$

${ }^{1}$ Doutora em Educação pela UFMS. Docente da Faculdade de Educação da Universidade Federal da Grande Dourados (UFGD), Dourado, MS, Brasil.

Resumo: Este estudo busca compreender a gestão na política educacional brasileira para a educação básica no Governo de Luiz Inácio Lula da Silva (Governo Lula), por meio de pesquisa documental e teórico-bibliográfica. Inicia abordando o Governo Lula e suas principais iniciativas para a educação básica e logo após apresenta suas ações voltadas para gestão da educação básica, concluindo que o Governo Lula apresenta iniciativas com mecanismos de gestão democrática da educação, tendo em vista uma formação para a cidadania, a participação dos cidadãos nas discussões, tomadas de decisões e materialização das ações de acordo com os seus anseios, mas também possui ações com mecanismos de gestão gerencial, que visam a um planejamento estratégico, eficaz, que possibilita a participação da comunidade escolar apenas na execução das tarefas previamente pensadas pela União e tem como fim a busca de desempenho e resultados na educação escolar, sendo estas as ações que possuem ênfase no Governo Lula. Na esfera normativa, a gestão democrática ainda é estabelecida como a concepção de gestão que deve vigorar na educação brasileira, entretanto vem ocorrendo a incorporação da gestão gerencial nas principais iniciativas da União nesse Governo.

Palavras-Chave: Educação básica; Gestão educacional; Política educacional; Governo Lula.

Abstract: This study aims to understand management in the Brazilian educational policy for basic education under the Government of President Luiz Inácio Lula da Silva (the Lula Government), through documentary and theoretical-bibliographic research. It begins by addressing the Lula Government, and its main initiatives for basic education. It then presents the actions of that Government for the management of basic education, concluding that the Lula Government presents initiatives with mechanisms of democratic management of education, with a view to training for citizenship, participation of citizens in the discussions, decisionmaking, and materialization of actions according to their wishes. But it also has actions with 
mechanisms of managerial management aimed at effective strategic planning that only allows for the participation of the school community in the implementation of the tasks previously thought of at Government level. Their purpose is the search for performance and results in school education, these being actions that were emphasized by the Lula Government. Thus, in the regulatory sphere, democratic management is still established as the management conception that should prevail in Brazilian education. Meanwhile, managerial management has been incorporated as one of the main initiatives of the Union in this Government.

Keywords: Basic education; Educational management; Educational politics; Lula Government.

Resumen: Este estudio busca comprender la gestión en la política educativa brasileña para la educación básica en el Gobierno de Luiz Inácio Lula da Silva (Gobierno Lula), por medio de investigación documental y teórico-bibliográfica. Se inicia abordando el Gobierno de Lula y sus principales iniciativas para la educación básica y tras presentar sus acciones dirigidas a la gestión de la educación básica, concluyendo que el Gobierno de Lula presenta iniciativas con mecanismos de gestión democrática de la educación, con vistas a una formación para la ciudadanía, la participación de los ciudadanos en las discusiones, tomas de decisiones y materialización de las acciones de acuerdo con sus anhelos, pero también posee acciones con mecanismos de gestión gerencial, que apuntan a una planificación estratégica, eficaz, que posibilita la participación de la comunidad escolar sólo en la ejecución de las tareas previamente pensadas por la Unión y tiene como fin la búsqueda de desempeño y resultados en la educación escolar, siendo estas las acciones que tienen énfasis en el Gobierno Lula. En la normativa de la política, la gestión democrática se establece como la concepción de gestión debe aplicarse en la educación brasileña, sin embargo, viene ocurriendo la incorporación de la gestión gerencial en las principales iniciativas de la Unión de este Gobierno.

Palabras clave: Educación básica; Gestión educativa; Política educativa; Gobierno Lula.

INTRODUÇÃO

A gestão educacional é tema recorrente na literatura educacional, principalmente a partir de 1988, com a introdução do princípio "Gestão democrática na forma da lei" na Constituição Federal de 1988 (BRASIL, 1988), e vem sendo reafirmada na legislação educacional vigente posterior a tal Constituição, mostrando que esta é a gestão que deve ser colocada em prática nos sistemas de ensino brasileiro.

Conforme Alves (2014, p. 22), a gestão democrática ${ }^{1}$ é considerada:

[...] um processo de caráter político-pedagógico e administrativo, no qual se dá participação efetiva, direta e indireta da sociedade em todos os níveis de decisão e execução da educação, com real poder de interferência e manifestação dos anseios comunitários.

Tem como base a participação, considerada como um meio pelo qual a população pode contribuir para atuar no governo da educação, no intuito de que este atenda aos seus interesses e possibilite o crescimento do indivíduo como cidadão.

Busca uma formação humana, uma educação de qualidade, a "emancipação dos envolvidos" e 
a "transformação das relações", já que se constitui em um ato de gerir a educação, que tem em vista o respeito dos direitos dos cidadãos, de sua maneira de ser, pensar e agir, proporcionandoIhes uma educação de qualidade e oportunidade e condição de produzir conhecimento.

Contudo, segundo Freitas (2007), tal normatização garante esta gestão como compromisso do Estado e da sociedade e, assim, dos governantes e administradores constitucionalmente estabelecidos, mas sua materialização depende de múltiplos e inter-relacionados fatores.

A partir dos anos de 1990, com a introdução de um projeto liberalizante e as transformações econômicas que vinham ocorrendo mundialmente, as ações voltadas para a educação passaram a apresentar características da gestão educacional gerencial e no Brasil essas características também passaram a ter espaço em sua agenda para a educação.

Segundo Castro (2007), a gestão educacional gerencial ${ }^{2}$ se constitui em um processo administrativo que adota diretrizes gerenciais e tem como base a busca de resultados e os indicadores de desempenho para a promoção do sucesso escolar. Enfatiza a eficiência, a eficácia, a efetividade, a autonomia, a descentralização administrativa, o mérito, a avaliação de desempenho e a produtividade e visa ao interesse público.

Castro (2008, p. 391) aponta que a gestão gerencial se caracteriza:

[...] pela busca da eficiência, pela redução e pelo controle dos gastos públicos, pela demanda de melhor qualidade dos serviços públicos, pelos modelos de avaliação de desempenho, por suas novas formas de controlar o orçamento e os serviços públicos e pela descentralização administrativa, que dá maior autonomia às agências e aos departamentos.

Segundo a autora, as estratégias de competitividade, o estabelecimento de parcerias e de envolvimento e participação ativa da comunidade local e escolar na definição e avaliação da escola estão sendo cada vez mais sedimentadas. Há um estímulo à participação ativa do cidadão nos serviços educacionais e à sua interferência na qualidade e na avaliação dos serviços públicos a partir de uma participação fiscalizadora e controladora.

Para Castro (2008), esse modelo de gestão educacional busca a melhoria da capacidade de gestão no intento de oferecer maior protagonismo à comunidade educativa local e um papel mais estratégico à administração central. Assim, admite a participação dessa comunidade escolar, mas como controladores e fiscalizadores das políticas públicas e como executores das tarefas previamente pensadas e planejadas.

Desta feita, neste estudo se buscou apreender a gestão educacional materializada na política educacional brasileira para a educação básica no Governo de Luiz Inácio Lula da Silva (Governo Lula) isso por meio de pesquisa documental e teórico-bibliográfica.

Inicia-se abordando as principais iniciativas do Governo Lula para a educação básica e logo após se abordam as principais ações desse voltadas para gestão da educação básica.

\section{O Governo lula e suas PRincipais ações Para A EDUCAÇão básica}

O Governo Lula foi iniciado no ano de 2003, mantendo algumas iniciativas da política do Governo FHC e rejeitando outras ${ }^{3}$. A priori, o Governo manteve a política econômico-financeira, como a política agrícola tradicional, e um ajuste fiscal (realizou, dentre outras ações, a reforma da Previdência Social), que propiciou os superávits primários e a independência de fato do Banco Central.

O Governo criou o Programa Nacional de Apoio à Modernização da Gestão e do Planejamento 
dos Estados e do Distrito Federal (Pnage); o Programa de Modernização do Controle Externo dos Estados e Municípios Brasileiros (Promoex); e o Conselho de Desenvolvimento Econômico e Social (CDES), mais conhecido como "Conselhão", no objetivo de realizar uma modernização democratizadora do Estado, a partir de um debate da sociedade com os formuladores de políticas públicas.

Mas, num segundo momento, adotou políticas sociais e uma política externa explicitamente inovadoras. Contudo, segundo Abrucio (2007), o estabelecimento de uma agenda para a reforma da gestão pública não foi um tema-chave nesse Governo.

No Governo Lula (período de 2003 a 2010), iniciou-se no Brasil uma nova fase de desenvolvimento econômico e social, com a combinação: crescimento econômico e redução nas desigualdades sociais. Nesse período, o Estado retomou o seu papel de estimulador do desenvolvimento e do planejamento de longo prazo, sendo essa a principal característica do mesmo nesse momento histórico.

Considerado um governo desenvolvimentista (BARBOSA; SOUZA, 2010; FRIGOTTO, 2011), o Governo Lula adotou medidas temporárias de estímulo fiscal e monetário no intento de acelerar o crescimento e expandir o potencial produtivo da economia; acelerou o desenvolvimento social por meio do aumento nas transferências de renda e elevação do salário-mínimo; aumentou o investimento público e reestruturou as carreiras e os salários dos servidores públicos; e ampliou o investimento público e a recuperação do papel do Estado no planejamento a longo prazo.

O Governo Lula ampliou o investimento em infraestrutura por meio de seu Programa de Aceleração do Crescimento (PAC), sendo esta uma de suas prioridades; reestruturou sua folha de pagamento com aumentos salariais para carreiras típicas do Estado; alargou a contratação de funcionários por meio de concursos públicos; e realizou a substituição de terceirizados por servidores públicos em atividade característica do Estado, com vistas a atender a uma determinação do Poder Judiciário.

Procurou aliar o crescimento e a estabilidade à inclusão social. Os programas de transferência de renda (Bolsa Família), os aumentos reais do salário-mínimo e o progresso horizontal do crédito concorreram para a estruturação de um mercado de consumo doméstico capaz de ancorar o ciclo de crescimento do país (BARBOSA; SOUZA, 2010).

Com a melhora das contas públicas e a redução da vulnerabilidade externa, foi possível a independência do Brasil no que tange aos organismos financeiros internacionais, com o pagamento da dívida com o FMI.

O incentivo fiscal e monetário concomitante às transferências de renda e ao aumento do investimento público recuperou o papel do Estado e acelerou o crescimento do país, possibilitando a realização da elevação dos lucros e dos salários, a geração de mais empregos nos setores formais e o alargamento da produtividade, bem como o aumento do PIB e o controle da inflação (BARBOSA; SOUZA, 2010).

O Governo Lula criou também diferentes instrumentos e arenas participativas no intento de instituir controle político e social dos agentes governamentais. Dulce (2010, p. 136) aponta que nesse Governo, 
[...] Tanto políticas estruturais, nas diversas áreas, quanto as decisões conjunturais mais relevantes são submetidas à análise da sociedade civil por meio de canais de interlocução com o Estado conferências, conselhos, ouvidorias, mesas de diálogo etc. -, que já constituem, na prática, um verdadeiro sistema nacional de democracia participativa. Políticas de desenvolvimento, de geração de emprego e renda, de inclusão social, saúde, educação, meio ambiente, juventude, segurança pública, direitos das mulheres, igualdade racial, democratização da cultura, entre tantas outras, foram discutidas em 63 conferências nacionais que mobilizaram diretamente, em suas várias etapas, mais de 4,5 milhões de pessoas em cerca de 5.000 municípios brasileiros - e são permanentemente fiscalizadas e avaliadas pelos conselhos de participação social hoje existentes em todos os municípios.

No Governo Lula houve uma abertura para a participação da sociedade no que diz respeito às políticas estruturais diretamente ligadas aos interesses da mesma.

Nele, além da possibilidade de discussão e da garantia dos direitos econômicos e sociais (emprego, salário, proteção social, educação e saúde públicas), foram introduzidos na pauta dessas discussões e garantias outros direitos, tais como: "efetiva igualdade étnica e de gênero, respeito a diversidade sexual, reconhecimento das demandas próprias de juventude, dos idosos, das pessoas com deficiência" (DULCE, 2010, p. 139).

O Governo criou órgãos específicos para o tratamento dessa nova geração de políticas, dentre eles, as secretarias especiais de Políticas para as Mulheres; de Promoção da Igualdade Racial; e de Direitos Humanos, que possuíam status ministerial e estavam diretamente ligadas à Presidência da República. Isso no intuito de disseminar de modo sistemático os valores da tolerância e do direito à diferença, com o objetivo de concorrer para a expansão do nível de consciência democrática do país.

Para Frigotto (2011, p. 240), no que tange à continuidade da política macroeconômica implementada no Governo FHC, a conjuntura da primeira década dos anos 2000, no Governo Lula, se diferenciou da década de 1990 em distintos aspectos, tais como:

[...] retomada, ainda que de forma problemática, da agenda do desenvolvimento; alteração substantiva da política externa e da postura perante as privatizações; recuperação, mesmo que relativa, do Estado na sua face social; diminuição do desemprego aberto, mesmo que tanto os dados quanto o conceito de emprego possam ser questionados; aumento real do salário mínimo (ainda que permaneça mínimo); relação distinta com os movimentos sociais, não mais demonizados nem tomados como caso de polícia; e ampliação intensa de políticas e programas direcionados à grande massa não organizada que vivia abaixo da linha da pobreza ou num nível elementar de sobrevivência e consumo. Trata-se, neste último caso, não apenas da realização de políticas compensatórias e de parca distribuição de renda, como é o Programa Bolsa Família, ou das políticas de descriminação positiva, mas do acesso diferenciado e intenso ao crédito para a casa própria e a bens de consumo, a programas de acesso à energia etc.

No que diz respeito à educação, o Governo Lula deu continuidade e aperfeiçoou o Sistema de Avaliação da Educação Básica (SAEB), o Plano de Desenvolvimento da Escola (PDE), o Fundo de Fortalecimento da Escola (Fundescola), o Programa Dinheiro Direto na Escola (PDDE), o Programa Nacional do Livro Didático (PNLD), o TV Escola, o Programa Nacional de Alimentação Escolar (Pnae), o Projeto de Melhoria da Escola (PME), o Prêmio Nacional de Referência em Gestão Escolar; e transformou o Fundo de Manutenção e Desenvolvimento do Ensino Fundamental e de Valorização do Magistério (Fundef) em Fundo de Manutenção e Desenvolvimento da Educação Básica e de Valorização dos Profissionais da Educação (Fundeb), ampliando o atendimento desse fundo para a Educação Infantil e Ensino Médio, já que o mesmo era destinado apenas ao Ensino Fundamental. 
Criou programas 4 voltados para a Educação Básica referente à formação dos profissionais da escola; à formação inicial e continuada para os professores; ao ensino fundamental de nove anos; à ética e à cidadania na escola; à saúde e à prevenção nas escolas e ao fortalecimento da educação escolar no semiárido.

Assim, o Governo Lula, apesar de ter aprimorado algumas políticas implementadas pelo Governo FHC, realizou inovações importantes no que concerne ao papel do Estado brasileiro no desenvolvimento econômico, social e cultural, a partir da distribuição de renda e da inclusão social; bem como na educação, ampliando as ações voltadas para a Educação Básica com vistas à melhoria de sua qualidade. A seguir, abarcam-se as ações desse governo indutoras da gestão educacional para a Educação Básica.

\section{Principais iniciativas do Governo lula voltadas para a GESTÃO DA EDUCAÇÃO BÁSICA}

O Governo Lula (período 2003-2010) realizou diversas políticas, programas e ações que, em sua maioria, a partir de 2003, foram reorientados, em função de ele ter pautado a sua atuação pelo princípio da defesa da educação de qualidade, a partir do binômio inclusão e democratização. Isso resultou em alterações nos marcos regulatórios vigentes para a Educação Básica e superior, uma vez que os mesmos, até então, estavam pautados sob a ótica gerencial e patrimonial (DOURADO, 2007).

A partir de 2003, o Ministério da Educação (MEC) implantou diversas iniciativas voltadas para a democratização da gestão da Educação Básica: Programa Nacional de Capacitação de Conselheiros Municipais de Educação (Pró-Conselho) ${ }^{5}$; Programa de Acompanhamento e Avaliação do PNE e dos Planos Decenais Correspondentes; ${ }^{6}$ Programa de Fortalecimento Institucional das Secretarias Municipais do Semiárido (Proforti); Programa de Apoio aos Dirigentes Municipais de Educação (Pradime)8; Programa Nacional Escola de Gestores da Educação Básica;; Laboratório de Experiências Inovadoras em Gestão Educacional10; e Programa Nacional de Fortalecimento dos Conselhos Escolares (PNFCE) ${ }^{11}$ (BRASIL, 2010c).

Esses programas buscavam proporcionar a democratização das relações na educação; o trabalho coletivo; a descentralização do poder; a autonomia; a participação qualificada, direta e por meio de conselhos de educação, da comunidade no tocante às políticas educacionais, à gestão educacional e escolar; e a mobilização desta no que concerne ao acompanhamento da educação e à elaboração de seus Planos de Educação, proporcionando-a a possibilidade de tomar decisões e participar das ações educacionais realizadas, refletindo, discutindo e propondo ações para a melhoria da qualidade do ensino, conforme seus anseios, por meio do aprendizado coletivo e do partilhamento do poder. Assim, apresentam como concepção de gestão educacional a democrática.

Outra iniciativa do governo federal foi a Conferência Nacional de Educação (Conae 2010), anunciada como espaço democrático de "edificação de diretrizes" para a política nacional de educação e de seus marcos regulatórios, na perspectiva da inclusão, igualdade e diversidade. 
Em abril de 2010, ocorreu a Conae 2010, com o tema "Construindo o Sistema Nacional Articulado de Educação: o Plano Nacional de Educação, diretrizes e estratégia de ação", que foi precedida por Conferências subnacionais baseadas no documento referência disponibilizado pelo MEC.

No que diz respeito à gestão educacional, o Documento Referência e o Documento Final da Conae 2010 reafirmaram o princípio constitucional de gestão democrática, concebendo-a como espaço de deliberação coletiva, que vise à garantia da educação pública de qualidade social e a construção de uma sociedade fundada na justiça social, na igualdade e na democracia; e como fator importante para a promoção da melhoria da qualidade da educação, bem como das políticas de Estado voltadas para a educação.

A Conae tinha como intuito discutir e propor metas e estratégias para o Plano Nacional de Educação, que começava a ser alterado naquele momento pelo MEC e pela sociedade civil. Contudo, paralelamente, encontrava-se em tramitação no Congresso Nacional o Projeto de Lei n. 8.035/2010, concernente ao Plano Nacional da Educação (PNE 2011/2020), que deu origem à Lei n. 13.005, de 25 junho de 2014, que aprovou o Plano Nacional da Educação (PNE 2014) quatro anos depois do início de tramitação do primeiro no Congresso Nacional.

No que se refere à gestão educacional, o PNE (2011/2020), em sua meta 7, apresenta como concepção de educação a democrática. Em sua meta 19, firmou que deve ser garantida, por lei específica aprovada em âmbito estadual e municipal, a nomeação comissionada de diretores escolares vinculada a critérios técnicos de mérito e desempenho, bem como a participação da comunidade escolar, com aplicação de prova nacional específica, com vistas a subsidiar a definição de critérios objetivos para o provimento dos cargos de diretores escolares (BRASIL, 2010a), o que não é característico da gestão democrática da educação, já que ela prevê somente a eleição de diretores como critério para o provimento de tal cargo.

Segundo Oliveira (2011, p. 335),

O projeto de lei em tramitação no Congresso PL n. 8.035/10, não traz com a mesma forca que o documento final da Conae a proposta de articulação entre os entes federativos rumo a construção de um Sistema Nacional de Educação; nesse aspecto e em muitos outros, ele se distancia do que foi acordado entre as muitas entidades que participaram ativamente da Conae e que subscreveram suas resoluções, revelandose um projeto tímido e pouco incisivo para apontar soluções para o grande nó da educação brasileira.

Assim, o intuito da Conae 2010, de se constituir em um "[...] horizonte para a formulação e materialização de políticas de Estado na educação, sobretudo, para a construção do novo Plano Nacional de Educação, período 2011-2020" (BRASIL, 2010b, p. 9), não teve o resultado esperado.

No que diz respeito à gestão educacional, a Conae 2010 apontou a gestão democrática da educação como um espaço de deliberação, já o Novo PNE apresentava a gestão democrática da educação relacionada à meritocracia e à busca de desempenho escolar, que, conforme a literatura educacional que trata do tema, não são características da gestão democrática da educação, havendo, assim, a ressignificação dessa gestão.

Em suma, as iniciativas voltadas para a gestão da educação antes mencionadas apresentavam mecanismos e ou procedimentos que são apontados pela literatura educacional como característica da concepção de gestão democrática da educação, no intuito de fortalecer essa 
gestão no âmbito das escolas e sistemas de ensino, havendo a predominância de processos formativos que almejavam qualificar os profissionais da educação, bem como a sociedade civil no que se refere a práticas e descentralização participativa, no intento de distribuir o poder, conforme pressupostos de um projeto político-participativo de governo.

Elas buscam a democratização da educação, estimulando a autonomia e a mobilização da comunidade, no tocante à sua participação nas ações e nas tomadas de decisões em todos os âmbitos da educação escolar em prol da melhoria de sua qualidade.

Mas o Governo Lula apresentou, também, iniciativas com mecanismos e procedimentos característicos da gestão gerencial, como o Plano de Desenvolvimento da Educação (PDE), o Plano de Metas Compromisso Todos pela Educação, o Programa Dinheiro Direto na Escola (PDDE), o Prêmio Nacional de Referência em Gestão Escolar, o PDE-Escola e o Plano de Ações Articuladas (PAR).

Essas ações enfatizavam a gestão gerencial, por meio da racionalidade técnica (acionada para tratar de questões de financiamento, de acesso e de prioridades) e a racionalidade substantiva (que promove políticas de transparência e de incentivo), já que tinham em vista a busca de resultados, tendo os gestores escolares apenas o papel de colocar em prática as ações preestabelecidas pelo governo federal. Nessas ações, a racionalidade substantiva, a partir dos resultados das avaliações em larga escala, focaliza objetivos e metas tangíveis em educação.

$\mathrm{O}$ PDE, que no Governo FHC era um programa do Fundescola, no Governo Lula se tornou um conjunto de programas e projetos desenhados pelo MEC para todo o país e passou a ter como intuito oferecer diretrizes, subsídios teórico-metodológicos, assessoria e acompanhamento às escolas e às Secretarias de Educação, no que se refere ao desenvolvimento de ações educacionais sistematizadas, em busca do sucesso e permanência do aluno na escola (BRASIL, 2007a).

No Governo Lula, esse Plano passou a compreender 52 ações, destinadas à Educação Básica, ao Ensino Superior, à Educação Profissional e à área de alfabetização (BRASIL, 2007a). Essas ações tinham como base seis pilares: visão sistêmica da educação, territorialidade, desenvolvimento, regime de colaboração, responsabilização e mobilização social.

Uma das ações desse Programa voltadas especificamente para a gestão educacional é o PDEEscola ${ }^{12}$, que se constituía num programa considerado eficaz no que diz respeito à melhoria da educação, que tinha como intuito a melhoria do desempenho dos profissionais da educação e dos alunos. Possuía diretrizes, mecanismos e procedimentos estratégicos de gestão uniformes para distintos ambientes escolares brasileiros, que deveriam ser apropriados e colocados em prática pelas escolas que a ele aderissem.

O PDE procurou reorientar a política educacional brasileira no Governo Lula, prioritariamente no que concerne à Educação Básica, tendo como condutor dessas ações o governo federal. Buscava-se, nesse momento, uma orientação comum que proporcionasse a integração da educação nacional e resolvesse os graves problemas dessa educação.

De acordo Saviani (2007, p. 1241), esse Plano "[...] aparece como um grande guarda-chuva que abriga praticamente todos os programas em desenvolvimento pelo $M E C^{\prime \prime}$, mas que não se articulava organicamente com o Plano Nacional de Educação em vigência, já que para o autor, 
as ações do PDE "[...] se relacionam com uma ou outra meta do PNE, deixando à margem a maioria delas. A conclusão que se patenteia é que o PDE foi formulado paralelamente e sem levar em conta o disposto no PNE".

Segundo Oliveira (2011), a partir do PDE, o governo federal buscou estabelecer um regime de colaboração que possibilite a repartição de competências e de responsabilidades, com a mobilização e a responsabilização de todos os agentes públicos envolvidos na educação e da sociedade civil; bem como o aumento dos indicadores educacionais, em especial, da Educação Básica.

Para a operacionalização do PDE, o Governo Lula fixou o Decreto n. 6.094, em 24 de abril de 2007, criando o Plano de Metas Compromisso Todos pela Educação que, segundo Camini (2010), não foi discutido simultânea e coletivamente, havendo participação apenas no decorrer de sua formulação e implementação. Para autora,

[...] de maneira geral verificou-se a elaboração de um plano sem ampla consulta e debate com as entidades científicasesindicaisdocampoeducacional-asquaistiveramreconhecidamentepresençadestacadanosdebates e na elaboração de projetos educacionais nas últimas décadas no Brasil Nesse sentido, não foi considerado o acúmulo histórico produzido pelos educadores organizados em suas entidades através do Fórum Nacional em DefesadaEscolaPública, as pautas discutidaseaprovadaseminúmerasconferências, congressos, asquaisforam discutidas e legitimadas pela sociedade desde o processo constituinte em 1987-1988. (CAMINI, 2010, p. 539).

Tal Plano tem como intuito a busca da melhoria da qualidade, aferida com base no desempenho dos alunos no Ideb. Busca a valorização do profissional da educação por meio do mérito e do desempenho, sendo essas iniciativas características da gestão gerencial.

Para a adesão a este Plano (ao termo de cooperação) e receber recursos financeiros e assistência técnica, os municípios e os estados brasileiros deveriam aderir ao PAR e elaborar um plano de atividades articuladas municipal e/ou estadual. Essa adesão significaria o compromisso dos gestores municipais e estaduais no que tange à concretização no plano local do Plano de Metas Compromisso Todos pela Educação, já que o $\mathrm{PAR}^{13}$, que é também uma das ações do $\mathrm{PDE}$, constitui-se em um planejamento multidimensional para a materialização das diretrizes e das metas deste Plano.

O PAR permitia escolhas restritas e direcionadas pela União por meio de opções limitadas. De acordo com Camini (2010, p. 540),

[...] a estratégia de envolvimento dos municípios e estados numa política nacional baseada em diretrizes já estabelecidas pode caracterizar-se como uma forma de democracia induzida ou consentida. Nesse caso, o órgão gestor central responsável formula a política a ser assumida e implementada em colaboração com as demais instâncias, propondo inclusive a forma de organização (equipe local, comitê de acompanhamento), apresentando através do instrumento do PAR um rol de ações e subações que podem ser escolhidas para execução, contando, para isso, com oferta de assistência técnica e financeira da União.

Assim, ele possui características da gestão gerencial, ao apresentar-se como um Plano que permitia aos municípios e aos estados que o aderiram escolhas restritas e direcionadas pela União por meio de opções limitadas, com tarefas previamente pensadas pela mesma, cabendo a eles apenas a autonomia na execução desse Plano.

Mas, segundo Camini (2010, p. 547), também apresenta características da gestão democrática, sendo elas: o incentivo à qualificação dos gestores escolares por meio do programa Escola 
de Gestores, citado anteriormente neste estudo, que apresenta uma concepção de gestão democrática da educação; e o incentivo à organização e à qualificação de conselhos de educação, tais como conselhos escolares, conselhos municipais de educação, conselhos de alimentação escolar e do Fundeb.

No que se refere à gestão educacional, o Plano de Metas Compromisso Todos pela Educação apresenta, dentre suas diretrizes, que a valorização do trabalhador deveria se dar por meio do mérito, por meio de seu "desempenho eficiente no trabalho, dedicação, assiduidade, pontualidade, responsabilidade, realização de projetos e trabalhos especializados, cursos de atualização e desenvolvimento profissional". Fixa regras claras a partir de mérito e desempenho, para a nomeação e exoneração de diretor de escola (BRASIL, 2007b). Tais iniciativas são características da gestão gerencial.

Aponta que os sistemas de ensino municipais e estaduais deveriam promover uma gestão participativa; elaborar planos de educação; propiciar o envolvimento de todos os professores na discussão e na edificação do projeto político pedagógico, conforme as especificidades de cada escola; fomentar os Conselhos de educação; e criar e apoiar os conselhos escolares no intento de envolver as famílias dos educandos no zelo pela manutenção da escola e pelo monitoramento das ações e consecução das metas do compromisso, como também em outras atribuições.

Segundo esse Plano, esses sistemas deveriam ainda acompanhar e avaliar as políticas públicas educacionais, com a participação da comunidade e do Conselho de Educação; bem como zelar pela transparência da gestão pública educacional com vistas a garantir o funcionamento efetivo, autônomo e articulado dos conselhos de controle social.

Em suma, tal Plano e o PDE têm como concepção de gestão a gerencial, pois têm vista a eficiência e a eficácia na educação, por meio da busca de desempenho e resultados na educação escolar, admitindo a participação da comunidade escolar e local no tocante ao monitoramento e à fiscalização da educação escolar.

Ambos atendem aos ditames dos organismos internacionais, bem como abrem espaço para a participação dos mesmos e do setor privado na política educacional brasileira, ao buscar mobilizar e responsabilizar todos os agentes públicos envolvidos na educação e da sociedade civil, no que diz respeito à melhoria do desempenho educacional brasileiro.

O carro-chefe do Plano de Metas Compromisso Todos pela Educação seria o PDE, e dentre as ações do PDE: o PDDE, que associa recursos adicionais à aprovação do projeto pedagógico da instituição; o Ideb, que afere a qualidade educacional, com base nas Diretrizes Curriculares Nacionais; e o PAR, que se constitui em um plano de ações, com apoio técnico e financeiro da União, para a melhoria da qualidade educacional.

Assim, esse conjunto de ações, mais especificamente a avaliação, vinha possibilitando um controle do desempenho do sistema escolar por parte do Governo Federal, se constituindo em um mecanismo de informação da eficiência e produtividade dos serviços educacionais.

Desse modo, o PDE estabeleceu conexão entre gestão, financiamento e avaliação, que conclamam a responsabilização (de todos os âmbitos da educação, do diretor escolar ao Ministro da Educação, por meio do Termo de Adesão ao Plano de Metas Compromisso Todos pela Educação; e da comunidade escolar e local) e, consequentemente, a mobilização social. 
No contexto do PDE, em particular no Plano de Metas Compromisso Todos pela Educação, as ações do MEC acentuaram o papel regulador da administração central e a gestão por resultados, sem desativar programas ${ }^{14}$ orientados para o fomento da gestão democrática.

Segundo Franco, Alves e Bonamino (2007), desde 2007 o Ideb e as metas a ele associadas, principalmente o PAR e o Plano de Metas Compromisso Todos pela Educação, eram os aspectos do PDE que teriam ganhado centralidade nas atividades do MEC. Tanto o PDE como o PAR seriam iniciativas que teriam como intuito a melhoria dos índices de desempenho dos alunos da educação básica, tendo como referência o Ideb.

Segundo o Inep (2008), a partir do Ideb se tornaria possível a ampliação das possibilidades de mobilização da sociedade em defesa da educação, já que o mesmo é comparável nacionalmente e exprime em valores os resultados mais relevantes da educação: aprendizagem e fluxo.

Nota-se que esse Índice poderia ser uma ferramenta importante para a efetivação de uma educação de qualidade com uma concepção de gestão educacional democrática, pois possibilitaria uma reflexão por parte da comunidade escolar e local sobre o que eles vinham aprendendo e o que se quer que eles aprendam.

Mas também poderia ser utilizado como um instrumento de competição, que ao mesmo tempo em que premia as escolas com bons resultados, pune as que não os possuem, apresentando assim características da gestão gerencial. Desta feita, o Ideb poderia servir tanto ao modelo de gestão democrática da educação como ao modelo de gestão educacional gerencial.

O Ideb foi inspirado no Programme for International Student Assessment (Pisa) - Programa Internacional de Avaliação de Estudantes - e passou a ser considerado a principal referência de governo para aferir a qualidade na educação, bem como organizar a educação nacional, já que mede o desempenho do sistema educacional, estabelecendo uma escala de zero a dez, no intento de mostrar as condições do ensino brasileiro. Para Oliveira (2011, p. 329),

[...] pode-se então considerar que o MEC buscou realizar e implementar uma política de Estado ao reunir programas de governo e atribuir orientação, integração e estabilidade a organização da educação nacional. Ainda que os objetivos perseguidos sejam discutíveis do ponto de vista do paradigma adotado - a eficácia do sistema -, a educação nacional passa a ser orientada na mesma direção, sendo a qualidade da educação básica referenciada no IDEB.

Com essa nova orientação, buscou-se a definição de uma política educativa comum no âmbito nacional. Contudo, houve a redução das possibilidades de autonomia e autodeterminação dos governos subnacionais no que diz respeito à organização do ensino, bem como uma orientação educacional quantitativa, centrada no alcance de metas e na busca de resultados, obtidos por meio de mecanismos de avaliação quantitativa do processo de aprendizagem que atingem, sobretudo, alunos, professores e gestores, exigindo das escolas e dos professores maior responsabilidade e performances compatíveis com tais metas,

[...] desconsiderando condicionantes históricos e objetivos, produzidos pelas políticas educacionais ou pela ausência do Estado no cumprimento do seu dever de ofertar ensino de qualidade para todos como um direito social. No caso brasileiro, os dados resultantes dos próprios testes/exames não têm evidenciado, em geral, uma melhoria na aprendizagem dos alunos, indicando que as alterações esperadas por intermédio dos testes/exames não vêm ocorrendo efetivamente. (OLIVEIRA, 2010, p. 93-94). 
Deste modo, a avaliação, por meio dos exames, se tornou um instrumento norteador da construção do projeto de educação nacional, bem como do trabalho dos professores e do financiamento da educação. A qualidade educacional, que tinha como base a formação para a cidadania, sendo vista como um direito social, passou a ser baseada nos resultados do Ideb. Oliveira (2010) aponta que a regulação por parte do governo federal no que concerne à educação deveria ser sinônimo de democracia e emancipação, materializada com a participação efetiva da comunidade escolar, segundo uma perspectiva de construção de aprendizagens significativas que tenha como base o projeto político-pedagógico da escola, edificado com a participação dos profissionais da educação e da comunidade escolar.

Contudo, segundo o autor, não foi o que ocorreu, pois as diretrizes e os parâmetros para a avaliação educacional, em geral externas e/ou internas à escola, não induziram e apoiaram um processo de avaliação da escola que levem em consideração, entre outros, a organização do trabalho escolar, a gestão democrática, as condições de oferta do ensino, o ambiente educativo, a prática pedagógica e avaliação, os processos de ensino-aprendizagem e a formação e condições de trabalho dos profissionais desta.

Nas palavras de Souza e Oliveira (2003, p. 881),

[...] o delineamento assumido pelo SAEB encontra respaldo em argumentos que se alinham na direção de justificar a avaliação como instrumento de gestão educacional [gerencial], tais como: possibilidade de compreender e intervir na realidade educacional, necessidade de controle de resultados pelo Estado, estabelecimento de parâmetros para comparação e classificação de desempenhos, estímulo por meio da premiação, possibilidade de controle público do desempenho do sistema escolar.

Assim, no Governo Lula a avaliação nacional, em especial o Ideb, mesmo podendo ser utilizado como mecanismo da gestão democrática da educação, vinha sendo usada como um mecanismo da gestão gerencial que tinha em vista a aferição do desempenho escolar no intento exclusivo da obtenção de resultados, já que seria considerado um indicador de qualidade educacional.

\section{Considerações finAis}

O Governo Lula criou e ampliou iniciativas voltadas para o crescimento econômico e redução nas desigualdades sociais, procurando aliar o crescimento e a estabilidade à inclusão social. Edificou, também, diferentes instrumentos e arenas participativas, com vistas a instituir controle político e social dos agentes governamentais, bem como ações que propiciam a discussão e a garantia de direitos econômicos e sociais, além de ter criado e ampliado programas e ações voltados para a Educação Básica com vistas à melhoria de sua qualidade.

No âmbito da gestão educacional, o Governo Lula apresentou iniciativas com mecanismos de gestão democrática da educação, tendo em vista uma formação para a cidadania, a participação dos cidadãos nas discussões, tomadas de decisões e materialização das ações de acordo com os seus anseios (Pró-Conselho; Programa de Acompanhamento e Avaliação do PNE e dos Planos Decenais Correspondentes; Proforti; Pradime; Programa Nacional Escola de Gestores da Educação Básica; Laboratório de Experiências Inovadoras em Gestão Educacional; Conae; Pnfce). 
Mas também possui ações com mecanismos de gestão gerencial, que visa a um planejamento estratégico, eficaz, que possibilita a participação da comunidade escolar apenas na execução das tarefas previamente pensadas pela União e tem como fim a busca de desempenho e resultados na educação escolar, sendo estas as ações que possuem ênfase no Governo Lula (PDE, PDDE, Prêmio Nacional de Referência em Gestão Escolar, o PDE-Escola e o PAR).

Em vez de priorizar uma educação voltada para democratização e emancipação, construindo-a com a participação da comunidade escolar e conforme os anseios desta, o referido Governo vem implementando uma gestão gerencial que tem como objetivo maior a obtenção de resultados, e não uma educação voltada para o desenvolvimento integral dos educandos, com uma formação crítica, humana, na qual estes sejam conhecedores e defensores de seus direitos e deveres.

Na esfera normativa, a gestão democrática ainda é estabelecida como a concepção de gestão que deve vigorar na educação brasileira, entretanto vem ocorrendo a incorporação da gestão gerencial nas principais iniciativas da União nesse Governo.

\section{REFERÊNCIAS}

ABRUCIO, F. L. Trajetória recente da gestão pública brasileira: um balanço crítico e a renovação da agenda de reformas. Revista de Administração Pública, vol. 41, p. 67-86, 2007.

ALVES, A. V. V. Fortalecimento de Conselhos Escolares: propostas e práticas em municípios sul-matogrossenses. Dourados-MS: Editora da UFGD, 2014.

BARBOSA, N.; SOUZA, J. A. P. de. A inflexão do governo Lula: política econômica, crescimento e distribuição de renda. In: SADER, E.; GARCIA, M. A. (Orgs.). Brasil, entre futuro e passado. São Paulo: Editora Fundação Perseu Abramo: Boitempo, 2010.

BRASIL. Constituição da República Federativa do Brasil. Brasília: Senado, 1988. Disponível em: $<$ http://www.planalto.gov.br/ccivil_03/constituicao/Constituicao Compilado.htm>. Acesso em: 15 maio 2015.

BRASIL. Decreto n. 6.094, de 24 de abril de 2007. Regulamenta a implementação do Plano de Metas Compromisso Todos pela Educação, pela União Federal, em regime de colaboração com Municípios, Distrito Federal e Estados, e a participação das famílias e da comunidade, mediante programas e ações de assistência técnica e financeira, visando a mobilização social pela melhoria da qualidade da educação básica. Brasília-DF: Presidência da República, 2007b. Disponível em: < http://www.planalto.gov.br/ccivil_03/_ Ato2007-2010/2007/Decreto/D6094.htm >. Acesso em: 20.jul. 2012.

BRASIL. Documento-final da Conferência Nacional de Educação: Construindo o Sistema Nacional Articulado de Educação - o Plano Nacional de Educação, Diretrizes, e Estratégias de Ação. Brasília: SEB/ MEC, 2010b. Disponível em: <http://portal.mec.gov.br>. Acesso em: 20 jul. 2011.

BRASIL. Laboratório de Experiências Inovadoras em Gestão Educacional. 2006. Disponível em: $<$ http://portal.mec.gov.br>. Acesso em: 26 jan. 2009.

BRASIL. Plano de Desenvolvimento da Escola - PDE. Brasília: SEB /MEC, 2007a. Disponível em: $<$ http://portal.mec.gov.br>. Acesso em: 26 jan. 2010.

BRASIL. Plano de Desenvolvimento da Escola - PDE. Brasília: SEB /MEC, 2007c. Disponível em: $<$ http://portal.mec.gov.br>. Acesso em: 26 jan. 2009. 
BRASIL. Programa de Acompanhamento e Avaliação do PNE e dos Planos Decenais Correspondentes. Brasília: SEB /MEC, 2005a. Disponível em: <http://portal.mec.gov.br>. Acesso em: 26 jan. 2009.

BRASIL. Programa de Apoio aos Dirigentes Municipais de Educação - Pradime. Brasília: SEB /MEC, 2005c. Disponível em: <http://portal.mec.gov.br>. Acesso em: 26 jan. 2009.

BRASIL. Programa de Fortalecimento Institucional das Secretarias Municipais de Educação do SemiÁrido - Proforti. Brasília: SEB /MEC, 2005b. Disponível em: <http://portal.mec.gov.br >. Acesso em: 26 jan. 2009.

BRASIL. Programa Nacional de Capacitação de Conselheiros Municipais de Educação - Pró-

Conselho. Brasília: SEB /MEC, 2003. Disponível em: <http://portal.mec.gov.br>. Acesso em: 26 jan. 2009.

BRASIL. Programa Nacional de Fortalecimento dos Conselhos Escolares. Brasília: SEB /MEC, 2004. Disponível em: <http://portal.mec.gov.br>. Acesso em: 26 mar. 2009.

BRASIL. Programa Nacional Escola de Gestores da Educação Básica. Brasília: SEB /MEC, 2005d. Disponível em: <http://portal.mec.gov.br>. Acesso em: 26 jan. 2009.

BRASIL. Projeto de Lei do Plano Nacional de Educação (PNE 2011/2020): projeto em tramitação no Congresso Nacional. PL no 8.035/2010. Brasília: Câmara dos Deputados, Edições Câmara, 2010a.

BRASIL. Secretaria de educação básica. Programas e ações. Brasília, DF: SEB, 2008. Disponível em: < http://portal.mec.gov.br/secretaria-de-educacao-basica/programas-e-acoes>. Acesso em: 20 set. 2009.

BRASIL. Secretaria de educação básica. Programas e ações. Brasília, DF: SEB, 2010. Disponível em: < http://portal.mec.gov.br/secretaria-de-educacao-basica/programas-e-acoes>. Acesso em: 20 set. 2010c.

CAMINI, L. A política educacional do PDE e do Plano de Metas Compromisso Todos pela Educação. Revista Brasileira de Política e Administração da Educação, v.26, n.3, p. 535-550, set./dez. 2010.

CASTRO, A. M. D. A. Gerencialismo e educação: estratégia de controle e regulação da gestão escolar. In CABRAl NETO, A.; CASTRO, A. M. D, FRANÇA, M; QUEIROZ, M. A. DE. (Orgs.) Pontos e contrapontos da política educacional: uma leitura contextualizada de iniciativas governamentais. origem e trajetórias. Brasília: Líber livro Editora, 2007. p. 115-144.

CASTRO, A. M. D. A. Administração gerencial: a nova configuração da gestão da educação na América Latina. Revista Brasileira de Política e Administração da Educação v.24, n.3, p. 389-406, set./dez. 2008.

DOURADO, L. F. Políticas e gestão da educação básica no Brasil: limites e perspectivas. Educação \& Sociedade, Campinas, vol. 28, n. 100, p. 921-946, out. 2007.

DULCE, L. S. Participação e mudança social no governo Lula. In: SADER, E.; GARCIA, M. A. (orgs.). Brasil, entre futuro e passado. São Paulo: Editora Fundação Perseu Abramo: Boitempo, 2010.

FRANCO, C.; ALVES F.; BONAMINO A. Qualidade do ensino fundamental: políticas, suas possibilidades, seus limites. Educação \& Sociedade, Campinas, vol. 28, n. 100. Especial, p. 989-1014, out. 2007.

FREITAS, D. N. T. de. Avaliação e gestão democrática na regulação da educação básica brasileira: uma relação a avaliar. Educação \& Sociedade, vol. 28, n. 99, p. 501-521, ago. 2007.

FRIGOTTO, G. Os circuitos da história e o balanço da educação no Brasil na primeira década do século XXI1. Revista Brasileira de Educação v. 16, n. 46, p. 235-274, jan./abr. 2011.

INSTITUTO NACIONAL DE ESTUDOS E PESQUISAS EDUCACIONAIS ANÍSIO TEIXEIRA. ÍNDICE DE DESENVOLVIMENTO DA EDUCAÇÃO BÁSICA - IDEB, 2008. Disponível em: < http:// portalIdeb.inep.gov.br/>. Acesso em: 12 dez. 2009. 
OLIVEIRA, D. A. Das políticas de governo a política de Estado: reflexões sobre a atual agenda educacional brasileira. Educação e Sociedade, Campinas, v. 32, n. 115, p. 323-337, abr.-jun. 2011.

OLIVEIRA, J. F. de. A educação básica e o PNE/2011-2020: Políticas de avaliação democrática. Revista Retratos da Escola, Brasília, v. 4, n. 6, p. 91-108, jan./jun. 2010.

SAVIANI, D. O Plano de Desenvolvimento da Educação: análise do projeto do MEC. Educação e Sociedade, Campinas, vol. 28, n. 100 - Especial, p. 1231-1255, out. 2007. Disponível em <http://www. cedes.unicamp.br>. Acesso em: 30 de abr. 2014.

SOUZA, S. Z. L; OLIVEIRA, R. P. de. Políticas de avaliação da educação e quase mercado no Brasil. Educação e Sociedade, Campinas, vol. 24, n. 84, p. 873-895, set./2003. Disponível em: <http://www.cedes. unicamp.br>. Acesso em: 15 maio de 2014.

Artigo recebido em: $24 / 08 / 2017$

Aprovado em: 25/10/2017

Contato para correspondência:

Andréia Vicência Vitor Alves. E-mail: andreiapepe@hotmail.com

NOTAS

1 Essa gestão tem como principais características: gerir pela comunicação, pelo envolvimento coletivo e pelo diálogo; transparência pública; eleição de diretores; impessoalidade; autonomia; trabalho coletivo; descentralização do poder nas instituições de ensino; participação direta e indireta da comunidade em todos os âmbitos da educação; eficiência; federalismo cooperativo; e cidadania crítica, política e social. Castro (2007) apresenta como principais características dessa gestão: o controle dos gestores e serviços públicos pela demanda de melhor qualidade e eficiência; a coordenação e a provisão de informações públicas em nível central; a necessidade de modernização da gestão; o planejamento e decisões estratégicas de governo; a burocratização; o controle gerencial; princípios de gestão estratégica e de controle de qualidade; mecanismos e técnicas de mercado; estruturas colegiadas; programas de emergência; desconcentração administrativa e de responsabilidades; separação entre formuladores e executores de políticas; modelos de avaliação de efetividade; o controle sobre os professores e administradores; o controle de resultados a partir de indicadores de desempenho estabelecidos; a responsabilização dos docentes, dos gestores da comunidade escolar pelos resultados alcançados; a falta de responsabilização do Estado de parte de suas obrigações com os serviços sociais; a ausência de compartilhamento do poder; e a qualidade como prestação de bons serviços.

3 "[...] as principais visões sobre economia no governo Lula podem ser divididas, grosso modo, em duas vertentes: uma mais próxima do chamado consenso neoliberal de política econômica e outra defensora de um papel mais ativo do Estado no desenvolvimento econômico e social" (BARBOSA; SOUZA, 2010, p. 67).

4 Programa de Formação Inicial para Professores em Exercício na Educação Infantil (Proinfantil); Programa de Formação Continuada de Professores das Séries Iniciais do Ensino Fundamental (Pró-Letramento); Rede Nacional de Formação Continuada de Professores da Educação Básica; Indicadores de Qualidade da Educação; Programa Gestão da Aprendizagem Escolar (Gestar); Programa Nacional de Valorização dos Profissionais da Educação (Profuncionário); Programa Ampliação do Ensino Fundamental para Nove Anos; Programa de Fortalecimento Institucional das Secretarias Municipais do Semiárido; Programa Ética e Cidadania; Pró-Licenciatura; Projeto Saúde e Prevenção nas Escolas (SPE); Programa Nacional de Valorização dos Trabalhadores em Educação Básica Pública; Olimpíada Brasileira de Matemática para as Escolas Públicas (OBMEP); Programa Nacional de Informática na Escola (Proinfo); Provinha Brasil e Prova Brasil (BRASIL, 2008).

5 Iniciado em outubro de 2003, esse programa tinha como compromisso a criação e/ou fortalecimento dos Conselhos Municipais de Educação em todo o país, buscando ampliar a capacidade de atuação dos conselheiros municipais de educação com vistas a incentivar e qualificar a participação da sociedade na tarefa de avaliar, definir e fiscalizar as políticas educacionais e, assim, garantir a universalização dos direitos básicos que promovam o exercício da cidadania (BRASIL, 2003).

6 Foi criado em dezembro de 2005 e se constituía em um programa de apoio técnico e pedagógico aos sistemas de ensino no que tange à formulação, à implementação e à avaliação de execução das ações realizadas do PNE e dos planos estaduais e municipais, com a participação da sociedade civil organizada (BRASIL, 2005a). 
7 Programa destinado aos municípios da região semiárida do Brasil, com vistas a propiciar subsídios que concorreriam para a eficiência, a eficácia, a obtenção de resultados e para a consolidação de uma cultura de participação na gestão educacional para que as gestões municipais da região atendam qualitativamente as necessidades educacionais de sua população, no intento de aprimorar a gestão educacional dos municípios da região semiárida do Brasil (BRASIL, 2005b).

8 Tem como objetivo apoiar e fortalecer de modo permanente a atuação dos dirigentes municipais de educação na gestão dos sistemas de ensino e das políticas educacionais e, também, contribuir para o avanço no que concerne às metas do PNE a fim de concorrer para o desenvolvimento da educação básica e da superação das desigualdades em nosso país (BRASIL, 2005c).

9 Constitui-se em um curso de especialização à distância oferecido preferencialmente ao diretor e vice-diretor das escolas públicas, buscando propiciar formação baseada na perspectiva da gestão democrática e da efetivação do direito à educação escolar pública com qualidade social, tendo como objetivo maior a inclusão social e a emancipação humana (BRASIL, 2005d).

10 Espaço de investigação e ferramenta estratégica que objetiva identificar, registrar, avaliar e disseminar promissoras experiências que possam ser desenvolvidas na gestão educacional dos municípios brasileiros, a fim de contribuir para a melhoria da qualidade do ensino público (BRASIL, 2006).

11 Por meio de apoio técnico e oficinas oferecidas aos técnicos e dirigentes da secretaria municipal, esse programa busca assessorar a implantação e o fortalecimento dos Conselhos Escolares nos municípios que com ele buscavam parceria, procurando garantir a efetiva participação da comunidade escolar e local na gestão escolar com vistas à melhoria da qualidade social da educação ofertada para todos (BRASIL, 2004).

12 Tal programa buscava firmar na escola uma gestão educacional baseada no controle de resultados mediante a introdução de um sistema de monitoramento e avaliação das iniciativas da escola definidas a partir de indicadores estabelecidos externamente, em especial do Ideb (BRASIL, 2007c).

13 A partir de 2008, o Par foi aderido por todos os municípios brasileiros.

14 Pró-Conselho; Programa de Acompanhamento e Avaliação do PNE e dos Planos Decenais Correspondentes; Proforti; Pradime; Programa Nacional Escola de Gestores da Educação Básica; Laboratório de Experiências Inovadoras em Gestão Educacional; Conae; PNFCE. 